\title{
OEPA Regimen
}

National Cancer Institute

\section{Source}

National Cancer Institute. OEPA Regimen. NCI Thesaurus. Code C67165.

A regimen consisting of vincristine, etoposide, prednisone and doxorubicin for the treatment of male patients with childhood Hodg kin's lymphoma. 